・书评・

\title{
两本《植被生态学》评介一一兼谈本土案例对 生态学教材的重要性
}

\author{
张 健 ${ }^{1,2 *}$ \\ 1 (华东师范大学生态与环境科学学院, 浙江天童森林生态系统国家野外科学观测研究站, 上海 200241) \\ 2 (上海污染控制与生态安全研究院, 上海 200092)
}

植被生态学是研究地表植物覆盖及其与环境 间相互关系的科学(van der Maarel \& Franklin, 2017)。作为生态学的一个重要分支, 植被生态学一 直是很多高校生态学专业本科生和研究生的必修 课。自1974年植被生态学的第一本教科书Aims and Methods of Vegetation Ecology (Mueller-Dombios \& Ellenberg, 1974)出版以来, 这个学科获得了极大的 发展。在我国, 林鹏(1986)、王伯蒜和彭少麟(1997) 以及宋永昌(2001)先后出版了植被生态学的中文教 材。在过去的10多年内, 植被生态学获得了长足的 发展。然而, 却没有看到新的相关教材出版。庆幸 的是, 2017年先后有两本植被生态学的中文著作出 版: 一本是华东师范大学宋永昌的《植被生态学》 (第二版), 另外一本是由云南大学杨明玉和欧晓昆 翻译的《植被生态学》(第二版), 原著Vegetation Ecology (2nd edn.) 由Eddy van der Maarel和Janet Franklin主编。下面结合我个人的学习体会来简要介 绍这两本著作。

\section{1 《植被生态学》(第二版, 宋永是著)}

该书由宋永昌教授撰写, 是2001年出版的《植 被生态学》教材的更新版本。在第二版中, 作者基 本保留了初版格式和内容, 但更新了近十多年中植 被科学领域的国内外最新研究进展。第二版共包括 18 个章节, 内容涉及植被生态学的发展史、植物群 落的组成与结构、群落与环境关系、植被动态、植 被排序与分类、植被分区与制图、植被的野外调查 方法以及植被生态学的应用。与初版相比, 增加的 主要内容包括：(1)原第8章“植被的动态”在新版中
分为两个章节，加强了对“植被历史”的介绍; (2)将 “中国植被分区”单独作为第15章, 增加了最新的研 究进展; (3)在其他章节也都结合最近研究进展增加 了相关内容: “植被保育、管理与恢复”(第1章)、“植 被资源清查与植被志编纂”(第1章)、“群落组建中的 生态位理论和中性理论”(第2章)、“植物群落一词是 否也适用于栽培植被的歧见”(第2章)、“谱系结构分 析”(第3章)、“群落中的物种共存”(第4章)、“植物功 能群”(第5章)、“排序研究进展及相关软件”(第10 章)、“植被分类的发展趋势”(第11章)、“不同调查方

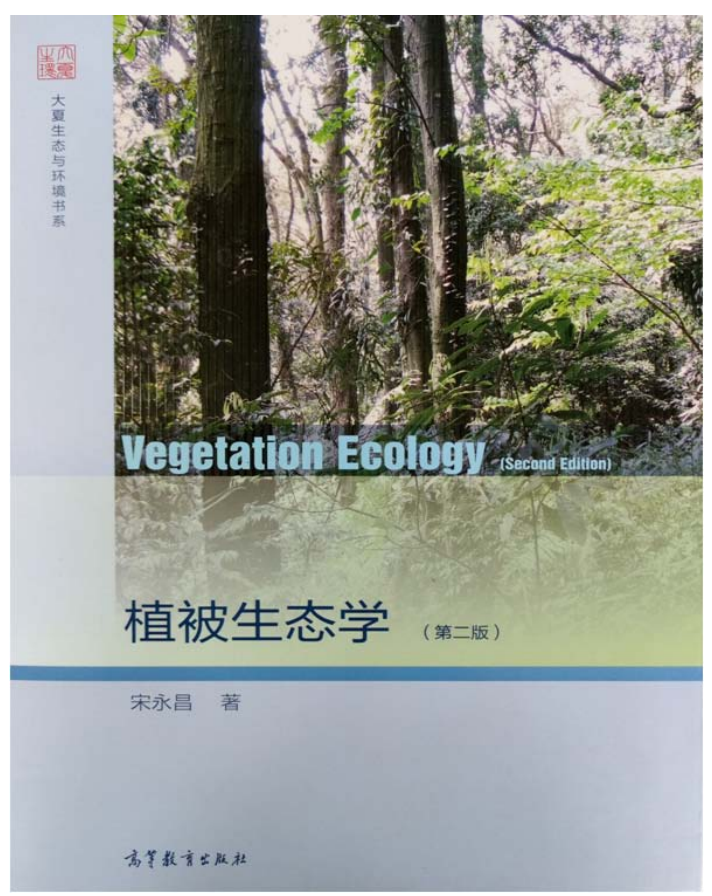

《植被生态学》(第二版, 宋永昌 著). 2017. 高等教育出版 社, 北京. ISBN: 978-7-04-046159-6.

* 通讯作者 Author for correspondence. E-mail: jzhang@des.ecnu.edu.cn 
法样地资料的统合”(第17章)、“植被生态学与全球 变化研究”(第18章), 这些都是当前植被生态学研究 的热点话题; (4)参考文献从初版的330篇增加到541 篇, 一方面反映了作者对学科发展的把握, 另一方 面也反映了植被生态学在最近 10 多年的迅猛发展。

\section{2 《植被生态学》(原著第二版, Eddy van de Maarel \& Janet Franklin编; 杨明玉和欧晓是}

该书的原著Vegetation Ecology第一版于2006年 出版，第二版于 2013年出版。主编Eddy van der Maarel先生是荷兰格罗宁根大学教授, 国际植被科 学学会前副主席, 植被生态学旗舰刊物Journal of Vegetation Science和Applied Vegetation Science的创 刊人之一, 他对植被动态与植被生态学在自然保护 和规划中的应用开展了很多奠基性工作。书的另一 位主编Janet Franklin女士是美国亚利桑那州立大学 教授，美国科学院院士，近年来对物种分布模型、 气候变化对生物多样性的影响等方面开展了非常 系统的研究工作。该书由33位作者共同完成, 共17 章, 内容既包括植被生态学发展历史和基本概念等 的介绍, 也包括很多最近的热点研究方向的详细介 绍, 如生物多样性与生态系统功能(第11章)、功能群 落生态学(第12章)、入侵生态学(第13章)、全球变化 与植被生态学(第17章)等。中文版由云南大学植被 生态学团队翻译完成。

\section{3 两本《植被生态学》的比较}

在研究内容上, 这两本教材都对植被生态学的 历史和最近的进展进行了非常系统的介绍, 但侧重 点各不相同:

首先, 相比较而言, 宋书在系统介绍的基础上, 对植被生态学的历史进行了更全面的阐述, 对于读 者了解学科起源与发展有很好的参考价值, 同时对 植被野外调查方法进行了非常详细的介绍, 并提供 了详细的调查方案、调查表格等, 为读者开展相关 野外调查工作提供了极大便利。而这些方面在van der Maarel的书中介绍得较少。van der Maarel书更侧 重于对学科前沿研究的介绍, 尽管这些前沿内容大 部分在宋书中都有涉及, 但介绍得比较简单, 而 van der Maarel书则用几个独立章节来分别介绍这 些前沿和一些新的研究方法和手段, 为读者提供了

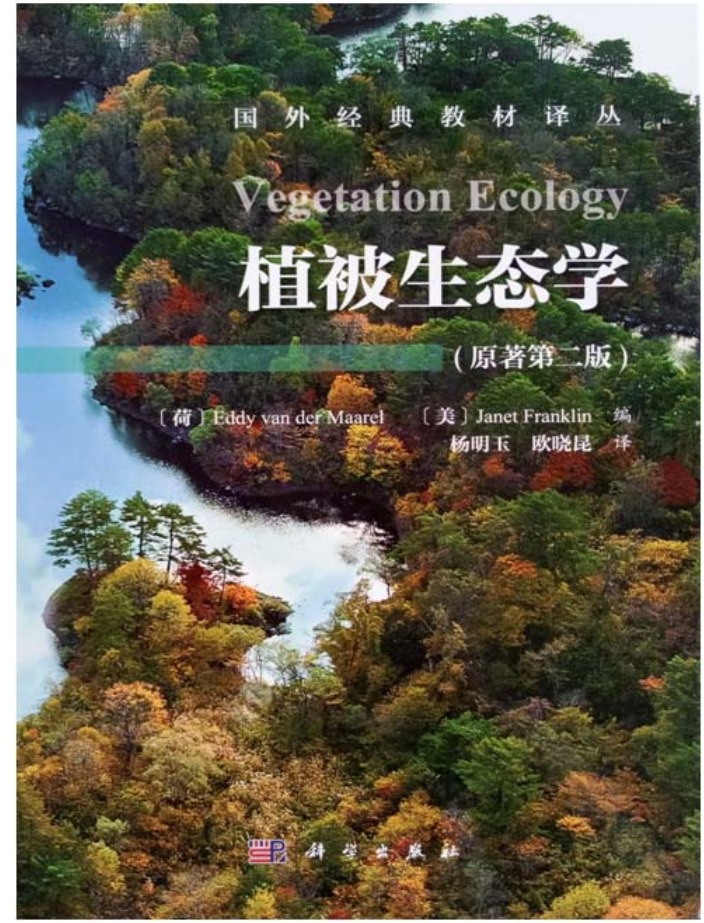

《植被生态学》(原著第二版, Eddy van der Maarel \& Janet Franklin编; 杨明玉, 欧晓昆 译). 2017. 科学出版社, 北京. ISBN: 978-7-03-051761-6.

一份难得的知识大餐。

其次, 宋书中包含了很多对于植被生态学在中 国的发展历程、中国植被分区等方面的详细介绍, 这是van der Maarel书中无法涉及的。从参考文献的 比较也可以看出，宋书中包括了很多中国植被相关 的研究工作, 但van der Maarel书中极少有中国学者 的工作。宋书中的这些文字和文献的梳理, 无疑对 于我国植被生态学的研究有着重要的参考价值。

第三，宋书中还包括了很多中国不同生态系统 的研究案例, 使国内的读者更容易理解和掌握相关 的知识要点。对于植被生态学这样一门理论和实践 相结合的学科来说, 本土案例显得尤为重要。一些 国外的教材在引进到其他国家时都考虑到了这样 的问题。例如, 美国科学院院士Robert Ricklefs所著 的教材Ecology: The Economy of Nature和Manuel Molles所著的教材Ecology: Concepts and Applications在引进到加拿大时, 增加了很多加拿大各生态 系统类型的案例(Ricklefs et al, 2014; Molles \& Cahill, 2014)。这一方式在中国引进的生态学教材中也 开始出现: Robert Primack等的Essentials of Conservation Biology的中文版《保护生物学》中加入了一 
些中国的研究案例, 如丹顶鹤(Grus japonensis)的 保护、在喜马拉雅地区阻止非法野生动物贸易等 (Primack et al, 2014)。基于课堂教学和翻译出版的 经验都表明, 适当地引入本土案例, 可以激发学生 兴趣和课堂交流(叶建圣等, 2014), 也可以促进大 学、国际组织、非政府组织之间的交流与合作, 建 立起理论与实践之间的桥梁(Primack, 2013)。

综上所述, 这两本教材对植被生态学的历史和 最新进展都有很好的呈现, 且各有特色, 互为补 充。总体而言, 宋书更适合于本科生或刚开始进行 生态学研究的研究生和研究人员, van der Maarel书 侧重于学科前沿, 适合高年级本科生、各阶段的研 究生和研究人员来了解学科的最近进展。通过这两 本书的比较让我们认识到中国植被生态学发展尚 存在一些问题与不足, 相信它们的出版对于该学科 的发展有着非常积极的推动作用。

同时，值得指出的是，两本书的两位作者现都 已超过 85岁高龄(宋永昌1933年生; Eddy van der Maarel 1934年生), 书中很多内容都是他们多年研 究工作的积淀, 在此向他们对植被生态学的贡献致 以崇高的敬意!

\section{参考文献}

Lin P (1986) Phytocoenology. Shanghai Scientific \& Technical Publishers, Shanghai. (in Chinese) [林鹏 (1986) 植物群落 学. 上海科学技术出版社, 上海.]

Molles MC, Cahill JF (2014) Ecology: Concepts and Applica- tions: 3rd Canadian Edition. McGraw-Hill Ryerson, Toronto.

Mueller-Dombios D, Ellenberg H (1974) Aims and Methods of Vegetation Ecology. John Wiley \& Sons, New York.

Primack RB (2013) Locally adapted textbooks can help biodiversity. BioScience, 63, 926-927.

Primack RB, Ma KP, Jiang ZG (2014) Essentials of Conservation Biology. Science Press, Beijing. (in Chinese) [Primack $\mathrm{RB}$, 马克平, 蒋志刚 (2014) 保护生物学. 科学出版社, 北京.]

Ricklefs R, Relyea R, Richter C (2014) Ecology: The Economy of Nature (Seventh Edition)(Canadian Edition). W. H. Freeman and Company, New York.

Song YC (2001) Vegetation Ecology. East China Normal University Press, Shanghai. (in Chinese) [宋永昌 (2001) 植被 生态学. 华东师范大学出版社, 上海.]

Song YC (2017) Vegetation Ecology (Second Edition). Higher Education Press, Beijing. (in Chinese) [宋永昌 (2017) 植 被生态学(第二版). 高等教育出版社, 北京.]

van der Maarel E, Franklin J (translated by Yang MY, Ou XK) (2017) Vegetation Ecology. Science Press, Beijing. (in Chinese) [van der Maarel E, Franklin J (杨明玉，欧晓昆 译) (2017) 植被生态学. 科学出版社, 北京.]

Wang BS, Peng SL (1997) Vegetation Science: Community and Ecosystems. China Environmental Science Press, Beijing. (in Chinese) [王伯䔉, 彭少麟 (1997) 植被生态学: 群落与生态系统. 中国环境科学出版社, 北京.]

Ye JS, Zhang R, Sun GJ (2014) Introducing China material to ecology foreign textbook when instruction: Take ecology curriculum as an example. Higher Education of Sciences, 114, 115-118. (in Chinese with English abstract) [叶建圣, 张荣, 孙国钧 (2014) 中国素材在外文教材授课中的重 要性研究: 以生态学课程为例. 高等理科教育, 114 , 115-118.] 